\title{
A Model for Communicating Social Problems: Perception, Knowledge, Incorporation, and Change
}

\author{
Andrea Volterrani \\ University of Rome Tor Vergata, Rome, Italy
}

\begin{abstract}
The article proposes a model to analyze, interpret, and construct the communication of social problems and everyday life. Four relevant aspects (perception, knowledge, integration, and change) of communication processes will be addressed, highlighting the issues to be addressed in light of the deep media coverage of our social world. In particular, it explores how perception changes profoundly in relation to the social conditions, groups, and communities to which one belongs. Furthermore, particular attention is paid to the difficult process of incorporation which allows concepts and social problems to become "family" through communication processes. Incorporation is a prerequisite for changing ideas and behaviors towards social problems. In conclusion, a strategy will be proposed to communicate social problems deepening dimensions and strongholds to be followed with particular reference to popularity and narratives in communication processes.
\end{abstract}

Keywords: communication, social problems, strategy

Cultural change has always been a central focus of social analysis. Understanding how and what symbols, values, and behavior change is to understand in depth changes and social innovations.

Communication is the catalyst and the core of this change, but often because of its characteristic of seeming naturalness, each individual and community tends to overlook and minimize the visible and invisible potential of communicative actions (Couldry, 2012).

As Couldry and Hepp (2017, pp. 34-35) also say, mediatization is a concept that helps us to critically analyze the interrelation between changes in media and communication on the one hand, and changes in culture and society on the other. The role of communication in history does not move like a relay-race, from one influencing medium to another. Rather, it is a continuous and cumulative enfolding of communication within the social world that has resulted today in ever more complex relations between the media environment, social actors, and therefore the social world.

This potentiality and intrinsic characteristic is even more important for the communication of social problems ${ }^{1}$. In fact, if communication is the main focus of the change in the buying patterns market, along with the strengthening and visibility of the brand, what often comes into play in social communication is the identity change of both the individual and collective.

Acknowledgements: The research and analysis work of the European project Oltre funded by the European Union-DG Home Call Police is at the base of the writing of this article.

Andrea Volterrani, Ph.D., professor and researcher, Department of Enterprise Engineering, University of Rome Tor Vergata, Rome, Italy.

${ }^{1}$ Communication of social problems is the communication related to everything that in people's social and daily life is vulnerable, marginal, difficult to face, and a bearer of obstacles to overcome. 
Furthermore, the object of change issues is often controversial and contradictory — for example, there may be communication campaigns to counter the risk of pathological gambling, yet there are also explicit and implicit messages inviting you to "try your luck" in some state lottery—from both scientific and common sense points of view, and sometimes, from a moral one as well (e.g., a campaign against homophobia which urges people who have very different value-convictions on the subject to change their opinion). Three different aspects—science, common sense, and morality—each involves differentially individual and collective social imaginary (Jedloswki, 2008, p. 134).

This is the first reason why coming up with and planning social communication is not simple: When you touch things that are part of our deepest convictions or which are taken for granted in our daily lives, every fact, interpersonal communication, or media that tends to problematize, you do not have an easy time of it. The "roots" of imagination are deep and firm, and are unlikely to be affected unless specific events capable of subverting ideas, meaning, and linked images occur. Furthermore, the change of the self in the era of deep mediatization is even more accentuated and intertwined with digital platforms (Van Dijck, Poell, \& De Waal, 2018) and with datification (Couldry \& Hepp, 2017, pp. 122-142; Couldry \& Meijas, 2019). From this we must try to understand the change of social imaginary processes in relation to the communication of social problems.

\section{The Processes of Change in the Communication of Social Problems}

The changes that can be connected to the communication of social problems are neither simple nor immediate. But in order to start an argument that is not just fatalistic, we must try to analyze the process that could lead to changes in the experienced reality. At least four different stages have been identified: (a) perception, selection, and relevance; (b) knowledge; (c) incorporation; and (d) possible change of attitudes and behavior (see Figure 1).

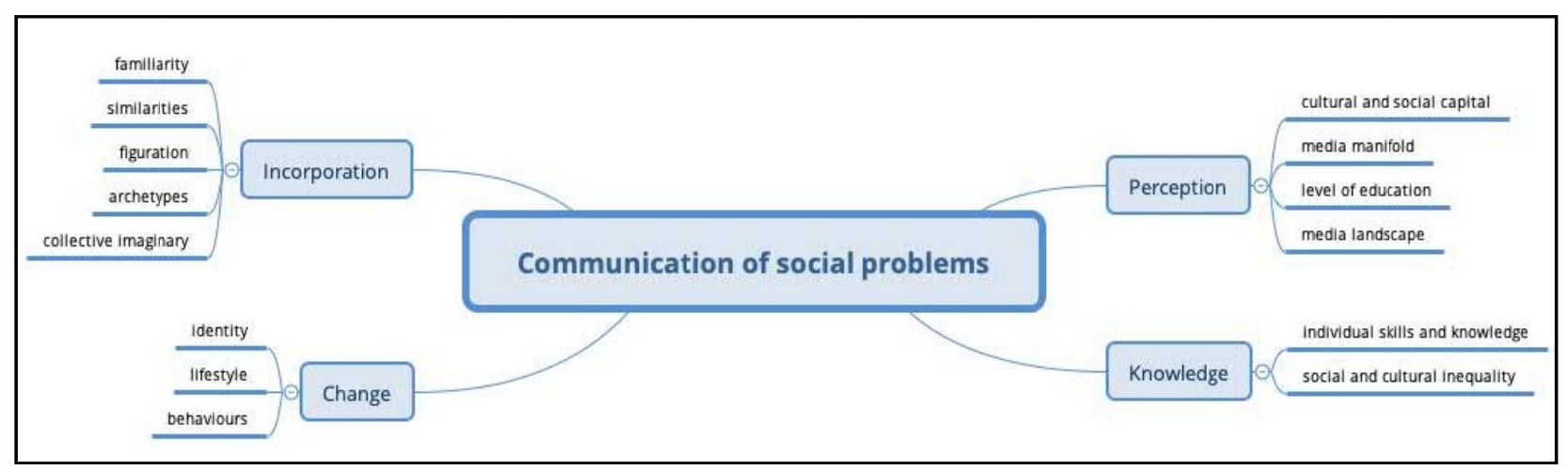

Figure 1. Model of communication of social problems.

\section{The Illusion of Knowledge: Between Perception and Knowledge}

The perception of the subject by an individual is an important step. For example, I may be horrified by a car accident, but I do not feel that I can be involved if I do not adopt a different behavior. However, finding that particular communication process which makes me "switch on" my eye is not easy. Seeing is the first step. Beyond theories of persuading that the ability to build messages that are more noticeable than others, the issue at stake here is another: my behavior and my attitudes. In the above example, it is not easy to see what image or video, such as sequences, or which safety issue in the road driving narrative will be most able to make me turn on the selection. 
Sloman and Fernbach (2018) have highlighted the problem of the illusion of knowledge, which is the fact that in most situations each of us is convinced that we know the details of what lies ahead and, instead, each knows what others know in depth.

In reality, we should say that each perceives what the others perceive and, perhaps, know. The distinction between perception and knowledge is fundamental for the reflection we would like to make. Perception is something that happens "in real time", while we are experiencing it, directly or mediatically. We can evade perception by turning our gaze in other directions (but in this case we would perceive other aspects that surround us) or, paradoxically, cancel all our senses and "cancel” external reality.

The social and communication problem that interests us is the impossibility of avoiding perception regardless of our desire to perceive or not a situation, an event, a context, or one or more people. This aspect, however, is connected to the fact that although we perceive what surrounds us in reality and/or mediatically, we are not interested in deepening all perceptions unless there is an imminent danger, we need to act after having perceived, or we think it could be useful later. We leave, either in the background or peripherally, what we are not interested in. On what basis is our selection built? There are many aspects that intervene in selective perception (Bentivegna \& Boccia Artieri, 2019) which are inherent to our occupation, our daily lifestyle, our aspirations, dreams, and desires; our problems and our opportunities, our relationships, the groups and associations to which we belong, the places and spaces of our lives, and our previous experiences. There are many variables that can influence the choice of perceptions that we consider relevant to us. From this perspective, cultural and social inequalities are extremely relevant for differentiation in perceptions: the lack of mastery of some cultural instruments, the intermittency with which some people deal with certain issues, and the profound inconsistency with their daily lives sharpen or diminish perception or they distort it in order to be able to appropriate it, albeit superficially. To this we must also add the digital inequalities that go beyond the purely technical digital divide, becoming a cultural digital divide that does not allow full accessibility to the completeness of perception (Bentivegna, 2009).

In the context just described, addressing this problem by invoking the need for completeness of information, the need for more detailed knowledge of the issues, is a way to hide the reality that, instead, most people live in: Among the multitude of information and communications, very few become relevant; the rest is forgotten, or at least distorted, modified, or integrated. And above all the knowledge will never be deepened because it is time taken away from other activities or from the knowledge of other priority aspects.

This inability to accept the reality of the perception by those who deal with social problems and social life (such as third sector and social economy organizations) can be partially explained with the complete involvement in the topic/problem they would like to be perceived. If I, as an organization, deal with the reception of refugees and asylum seekers within a structure, I will have a perception and detailed knowledge of the characteristics, problems, and aspirations of the people I am welcoming. If I pretend that this type of perception and knowledge about refugees is also the heritage of the territorial community, I have not understood how processes and communication practices work. These aspects are continually repeated in essentially the same way in multiple organizations that prefer to concentrate on communicating their service to their users rather than working on communicative relationships with the community.

The vicious circle that triggers self-referentiality and claiming against those who do not perceive/understand is particularly strong. To this is often added a further claim with respect to the media system that is incapable of adequately representing the themes and problems of third sector organizations. 
To break these dual symmetries, it becomes necessary to "make the horse move" or to shift the attention to the problem of perception by addressing the issue of inequalities on the one hand and on the other, the question of the construction of dialoguing relationships that allow the initiation of a mutual communicative recognition path.

Some might argue that this situation could be possible at the level of small communities, but if we move to a national or international level, the role of the media becomes central in building framing processes and agenda setting with respect to social issues and problems. The reasoning is certainly correct because some social themes and problems are interpretable only if we remain within frames that the media help to create through, for example, the use of metaphors that allow a simplification that interacts profoundly with the individual imaginary and collective (Ervas \& Gola, 2016; Lakoff, 2014). Still the mediated construction of reality (Couldry \& Hepp, 2017) is not only a concept dear to academics, but a process that has expanded more since the digital revolution and, in particular, with the development of the so-called platform society (Van Dijek et al., 2018). It is through the platforms that our daily lives take shape and develop without interruption through relevant communication processes as much as those face to face. In this continuity between on- and off-line (Boccia Artieri, 2016; Boccia Artieri, Gemini, Pasquali, Carlo, Farci, \& Pedroni, 2017), each of us is completely immersed in both a continuous construction and reconstruction of social ties and in representing the "best side" of ourselves as well as being protagonists of communicative practices aimed at adding perception and knowledge for us and for others (Couldry, 2012).

\section{Quantity or Quality of Communication?}

The dilemma is badly posed. Surely the amount of communication on a given theme or social problem increases the individual and collective perception, albeit with the limits we have highlighted. The cross-media and the daily allow perceiving to those who want. But if the communication is qualitatively poor, unprofessional, and/or incapable of arousing the curiosity necessary to deepen it, the result risks being too little productive in order to pass from perception to knowledge of the theme/problem. Generally, within third sector organizations, it is a question that is liquidated only in terms of resources: for quantity and quality, economic and professional resources that are needed but are not easily accessible.

\section{The Social Imaginary Between Perception and Incorporation}

But then what do we perceive as social imaginaries? And how is it possible to change the perception, going beyond the difficulties we have highlighted? These are two questions that are closely related to each other.

Social imaginaries are a set of symbolic and value representations, of direct and mediated experiences, emotionally oriented and stratified over time by objects, spaces, and social flows. They are spaces of reality constructed mediatically, which third sector organizations and, more generally, all of us have to do on a daily basis. When we meet people with disabilities, we build a relationship that refers to the reality experienced directly but also to that built on disability over time with ideas, stereotypes, and representations. It is not a problem of which of the two is more relevant than the other because they co-operate simultaneously to strengthen, modify, and integrate our perceptions and knowledge. Nor is it a deterministic mechanism (cause-effect) that helps to clarify how a social imaginary is constructed, but rather a continuous individual and collective construction/reconstruction that continually accompanies us in our lives. 
Let's go back to our initial questions and let's try to clarify some aspects. First, we perceive those parts of the imagination that are contingently most useful to us in the relationships we are experiencing in the present. Staying with the disability example, in the relationship with people with disabilities I will initially use those parts of the social imaginary on disability that help me overcome the fear of diversity (rarely the danger of diversity), a profound archetype that makes us wary of that which we do not know. Secondly, I can perceive, if it is not the first experience, the differences between people with the same disability or with different disabilities. I perceive the nuances that can help me to deepen the relationship towards the knowledge of disability. Thirdly, I can perceive the complex issues of people with disabilities in their completeness and accuracy. Social imaginaries are a resource for the perception that can be activated by each of us with variable geometries and are a resource present in a different way in the collective and, most importantly, individual imaginations.

The change in the perception of social imaginary is in most situations a temporally long process. The stratification of representations and experiences that collectively accumulate has a persistence and a compactness that can be modified only with other layers of representations and different experiences of symbols, values, and meanings. This does not mean that it is easy to replace one framing process with another simply through well-constructed social communication strategies. It is indeed a process that involves slow, gradual, and broad development, alongside the pre-existing ones of different representations and direct and mediated experiences. There is also the possibility that sudden fractures occur in the framing caused by exceptional and popular events that distort the stratifications established up to that point. An example is the image of the dead migrant child lying facedown on the shore of a beach that has at least partially contributed to drawing more attention to the problem. In reality, after a short time and due to the absence of other possible representations, the framing reverts back to the previous one.

So, are perceptions difficult to change? If we want persistent changes over time and lasting effects, we cannot ignore that the processes must involve a large number of people and, above all, that they must take into account the individual and social characteristics of each of those people. The processes by which we interpret and select media content are very complex (Couldry, Livingstone, \& Markham, 2010). One on which it is important to dwell is that the role of individuals, and the communities to which they belong, is an established element in the interpretation to be taken into account in social communication. It is a delicate phase that is not attributable only to the visibility of the issue or problem, but also to the ability and symbolic resources that individuals possess. These are not distributed evenly within the population nor do they reproduce the same social and territorial family and economic contexts. Next comes the problem of cultural inequalities at stake (Bentivegna, 2009), a problem which, along with that of social inequalities, has been too often overlooked or relegated to the margins of reflection in recent times. If I do not have sufficient or adequate cultural and symbolic resource perception, the significance and the selection will be strongly affected, and in some cases, severely limit the opportunities that could be seized. For example, it is known that good nutrition prevents serious health problems. However, it is also known that those who have greater economic and cultural deprivation tend to underestimate the problem, and thus poor nutrition adds further problems to existing problems.

\section{Knowledge}

This aspect is closely linked to the second phase of the process of change, knowledge. The transition from the perception of the theme's relevance to knowledge is primarily a growth of awareness of the need to deepen, 
individually or collectively, a certain aspect in which I/we are concerned. In this case as well the path is not deterministic but connected to both the characteristics and individual resources that are available across all media and interpersonal relationships. Neither aspect can be taken for granted but, in fact, possess considerable difficulties, even when everything else would tell us otherwise. A striking example is the knowledge that should result from communication processes in risk or crisis situations due to natural disasters. Even during those moments which are critical for physical survival, the initial problematization does not automatically switch to the knowledge of what should be done (Horsley, 2016). Despite seismic risk awareness, few of us remember that there are small things you can do in your own home, such as securing everything on the walls. Those involved in risk communication and prevention tried to come up with and plan complex models that provide a strong activation of local communities and a strong involvement of people who could potentially be interested in such knowledge, with particular reference to the most vulnerable social situations (Volterrani, 2016). For example, the involvement of people with disabilities may not only be "on paper", but stem from a detailed one-to-one relationship that increases the degree of risk knowledge and the consequent ability to implement what is necessary in order to prevent problems.

The implications with respect to knowledge are even more profound if we consider that the production of knowledge today no longer passes only through face-to-face relations, but also through digital platforms and, more generally, datification (Couldry \& Hepp, 2017, pp. 122-142). The consequence with regard to the communication of social problems is particularly important because the datification is also accompanied by a profound acceleration of social life (Rosa, 2013) and by a superficiality and speed in the circumstantial interpretation of what surrounds us. Such a profound change cannot be avoided if we want to try to develop a more in-depth reasoning about the possibilities of change. But an even more relevant element is the one we will discuss in the next section.

\section{Incorporation}

Knowledge alone, however, is not sufficient to prompt a possible action. The next step is incorporation. Some scholars of cognitive psychology (Hofstadter \& Sander, 2011) have highlighted the way in which humans expand their wealth of concepts and terms in their own world of thought. The tool we use to categorize the outside world is the analogy, i.e., reading the external environment with the categories we already have in our heads and in our daily life experience. The incorporation of new concepts and new experiences is through comparisons and comparisons (note similarities) with what we have in our heads and what we think comes closest to the new issue we are facing. It is evident that absolute novelty will have more difficulty of being incorporated than new minor or simple variations on already known themes and problems. For those not raised in Italy, the bidet is an object and a concept which is not easy to incorporate (or even to comprehend), but it is easier than trying to imagine what it is like to make a crossing without economic resources in the hold of a jam-packed boat always on the verge of sinking. It is perhaps the most important aspect of change through the communication process because it leaves little room for innovation and deep trends. We tend to consolidate what we know well and distrust what we do not know. No wonder this reasoning because the survival of the species is closely linked to the ability to read and assess the dangers posed by the unknown. The archetype of fear of the new and different is rooted in our collective imagination and is an integral part of human history (Durand, 1960). This does not mean that we do not possess the cultural tools to overcome this archetype, but, returning to the reflections on cultural inequalities, it is unthinkable that we all possess the same means. It is 
much easier to say, "We've always done well" or "There is nothing much to do; it's fate" than evaluate alternatives and possibilities, and build visions and different horizons (Vergani, 2012) on the subject or the problem to be addressed.

Furthermore, it is fundamental to underline that the social construction of reality today, profoundly influenced by the media, also modifies the processes of incorporation. Couldry and Hepp (2017) use the concept of figurations by Norbert Elias (1978) to describe the forms that interdependence and interactions between individuals take and how meaning and interpretation are produced in a context of deep media and digitalization. The incorporation, therefore, also changes through analogies that are produced individually and collectively within the figurations. In the case of social problems this aspect is particularly relevant because the issues are deeply immersed in the figurations built both in digital media and in everyday social life, with continuous feedback of reciprocity full of contradictions and different interpretations that make the shared incorporation of concepts even more difficult.

\section{Change}

The fourth and final phase is the action of change. This is a delicate phase because the action of change may have effects on both the individual and collective level and can be real or imaginary. Individual change is more complex because it involves a "revolution" in the behavior or attitudes of our daily lives. If, for example, we think of how challenging it is for individual smokers to quit smoking despite a large presence of information and empirical evidence, we can understand that this step, which is often considered to be "simple", has, however, many elements of complexity to be explored. The most common expression is, "I want to stop smoking because it's bad for me, but I can't". Another argument is the change of the collective imagination which, though complex, can be achieved more easily. In fact, this is closely connected with local cultural change or the collective imagination on the subject. Also in the case of smoking, the growing prohibition of spaces available for smokers has been "accepted" as a positive change, even by smokers themselves, without protest.

The process of change can be connected to communication of social problems, and therefore, is complex and articulated. If we add to the difficulties of interpersonal and media communication processes that are now an integral part of the studies on the audience (Murray, Schrøder, Drotner, \& Kline, 2003), we understand that the challenge is difficult but very attractive to those who care about improving the quality of life of our communities.

\section{The Problem of Media Manifold}

From the point of view of social problems, reasoning on the change in the communication process means, therefore, trying to operate in order to innovate the public imagination in the direction of an enlargement of the symbolic resources available to individuals and communities of often complex and contradictory issues and problems, such as social ones. Opening the imaginary means making the images, ideas, and values that would otherwise remain marginal in our heads available and accessible to most people.

Couldry describes the concept of media manifold as follows:

Our suggestion is that this double concept well captures the doubleness of our embedding in today's extremely complex media universe. The broader set of media and information possibilities on which each of us can draw is almost infinite, and certainly organised on very many dimensions. In everyday practice, we choose, from moment to moment, 
from a reduced set of possibilities which actualizes, for daily usage, a pragmatic selection from that many-dimensional media universe. What we do with media, moment to moment, actualizes those further choices. There are therefore three levels. Yet, as we try to understand our relations as choosing actors to the wider universe of media, it is the first two levels (and their interrelations) which most concern us. The necessary relations between the first two levels are summed up by characterizing our relations with media in a two-level way, as relations with a "media manifold”. (2016, pp. 31-32)

Within the multiple choices, the reduction that we operate does not often contemplate the choice of receiving, reading, and investigating the social problems that often remain on the margins even of the average manifold at our disposal. Many features of contemporary common sense are produced by the media manifold, which feed and reinforce ways of speaking and thinking, lifestyles. This is not to make a generic accusation of superficiality and banality, but rather to highlight the potential role it plays in people’s lives. Socialization, first of all, is against those who have lifestyles and especially consumers in the western world. Anticipation of what the future might be, or rather the idea of the individual and collective future. It is an imaginary reserve from which to draw inspiration for the construction of identity (Silverstone, 1994). It is evident that communication of social problems, as we have described it up to now, cannot remain on the periphery of the media manifold, cannot build a symbolic universe apart, but must instead promote a real colonization using homogeneous technical and quality standards and what is likely to contaminate and replace, symbolically and culturally, part of the media manifold. A positive example of the process of change is that of the perception of the care of the environment as a determinant for overall well-being (Peruzzi \& Volterrani, 2016, p. 150). Despite the conduct not always being consistent, ecological awareness has reached the heart of the media manifold within the last 30 years. The same reasoning cannot be said of the rampant issue of child poverty in African countries where the awareness has not turned into incorporation, or even, produced the "stolen letter effect"; that is, objects that are right in front of everyone's eyes but go unnoticed.

Precisely for this reason it is even more necessary to share this vision of communication of social problems in a cultural context which is often used to think that the important issues are very different.

All of this is adversely affected if we design communication of social problems with a completely different approach from the other types of communication: participation.

\section{Participatory Communication of Social Problems: An Essential Prerequisite}

Communication of social problems cannot exist without participation. At the same time, it is both a problem of democratic participation (Sorice, 2019) and of links between participation, communication, and territorial communities (Volterrani, 2018). For the first question, it is fundamental that the issues related to social problems are discussed within democratic participatory and communicative processes in order to involve a larger number of people. For the latter, it is often in degraded urban suburbs, but also in other territorial communities where it is necessary to develop communication processes capable of involving all citizens starting from the holders of the problem, the interests of users, and the producers of communication. A triangle is crucial if we want to trigger at least the start of the change processes we mentioned. If you want to increase blood donation among young people, it is not enough to just construct communications campaigns "aimed" at them, but you must also construct occasions where the young people themselves are the protagonists.

Engagement is not just an observation of a different use of the media by the public, but one of the roads that promotes awareness and involvement in the citizens of a community (Dahlgren, 2009; 2013). And it is the first step before moving on to the knowledge, incorporation, and action for change. 
Participation needs its own time and its own rules (Curran, 2011) to give space to all those who intend to take action. However, communication of social problems does not mean slowing down but enriching and articulating content and mode of use.

Working on participatory communication of social problems, starting from the construction, and sharing of social representations and social imaginary, is a pretty unique perspective.

The process planning-social imaginary and social-engineering-communication of social representations, in fact, does not stop at the first change of the imaginary and social representations but continues if the contributions of groups of people and the points of view are activated and implemented in a systematic way. The result is a communicative planning that continues and is able to constantly renew itself, thereby increasing the participation and involvement of new groups of people.

The multiplication of participating groups has a positive effect on local communities. It is the participation communication of social problems projects that changes perceptions and actions, and therefore, also semantic maps. For example, if I want to change young people's relationship with alcohol, I have to try to rebuild their perceptions and their imaginary, submit them, and be ready to change them again in order to understand where to direct the communication and, especially, how to build it. You redraw the conceptual boundaries of some issues along with other social or individual identities not by basing them on a simple argument but on a responsible involvement in the community or territory. It is a way of enhancing those roots within the vital world and common sense, of being in the world of everyday life that characterizes at least a part of civil society and the third sector.

\section{New Communication Strategies on Social Problems}

If this is a plausible picture, what could the new communication strategies for organizations (public and non-profit) interested in the change of social imaginary be? See Figure 2.

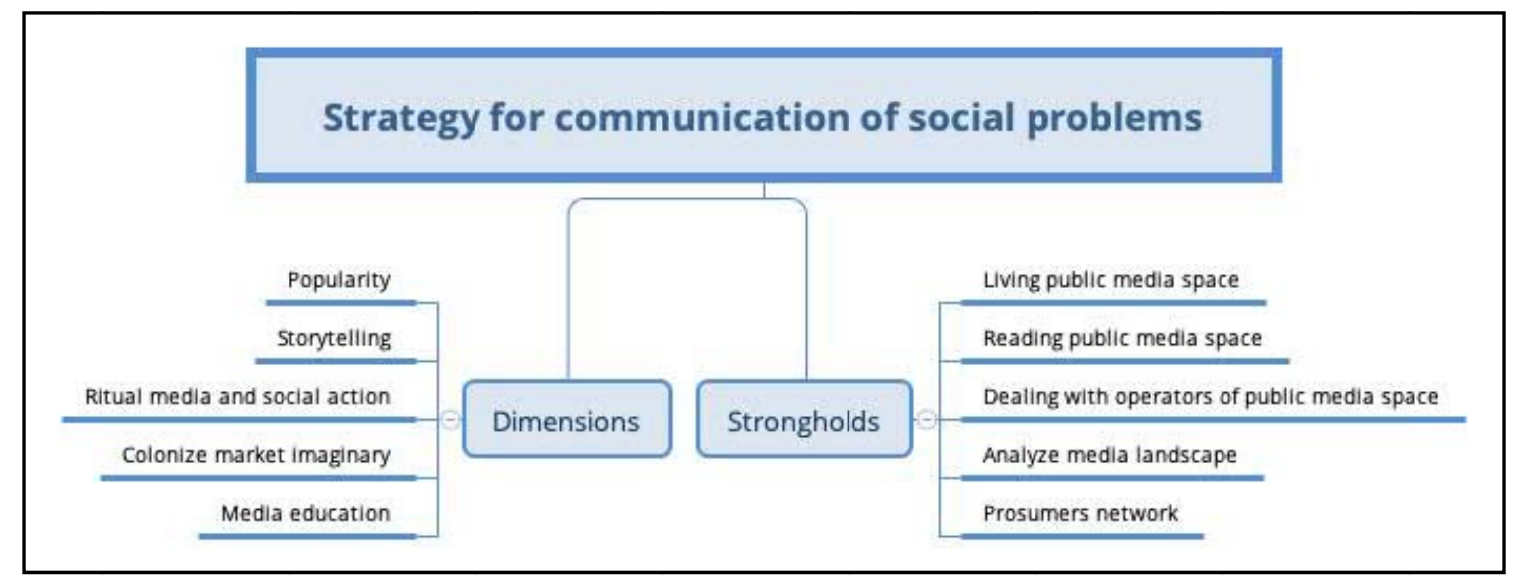

Figure 2. Strategy for communication of social problems.

\section{Strategy's Strongholds}

The first stronghold is monitoring the media public space daily—not only journalists, but also television (national and local) and the Internet - in order to be able to appropriate the narrative styles, symbologies, and prevalent proposals from major manufacturers of the imaginary. Mastering the mainstream is essential in order to build a communication of social problems that goes beyond. 
The second stronghold is reading the medial public space concerning social themes with detachment in order to highlight not only contradictions and shortcomings, but also symbols and rituals. On occasion, some people talk about the absence of social issues without assessing their presence in narratives and imaginary places, such as television series, which are rarely visited by the organizations (public and non-profit) but often frequented by people and communities (Buonanno, 2008). A key prerequisite for any communication of a project geared towards a social problem is the rebuilding of the media outlets with the topic of our interest.

The third stronghold is dealing with the operators of public space media (journalists, producers, writers, and directors) in order to understand dynamics, languages, styles, and working routines, especially with regard to the production of TV series and serials. It becomes a credible interlocutor when there is a need, for example, to construct new narratives by television writers. There are no permanent confrontation areas, and if there is a change in media narratives, it is related more to a transformation of the authors, writers, and scriptwriters than to an initiative taken by organizations.

The fourth stronghold is analyzing and continuously monitoring the media landscape of our membership organization's subject of interest, and then to go and explore different points of view away from it, to see and learn the ways that others learn the imagery of the subject that interests us. We will be surprised by how the social imaginary also extends to those who are most distant from those other individuals who are fully involved in communication actions on the subject.

The fifth stronghold is the construction of a network of small prosumers (Jenkins, 2006) capable of multiplying the communicative contents of the social problem on which we believe it is necessary to initiate a process of change in the collective imagination with handcrafted professionalism (Sennet, 2008).

\section{Strategy's Dimensions}

Based on these strongholds, how can we build a sensible strategy in the communication of social problems?

There are five dimensions to consider as cornerstones. We must inspire communication actions to a popularity that can be achieved if we put ourselves in the shoes of others (even when we do not like them) and share their thoughts and their imagination.

(1) Putting yourself in the shoes of others. Put yourself in the "shoes" of the means of understanding the mechanisms, styles, languages, and popular places in the medial public space. Of course, you may think this means, for example, speaking to those who care about their own issue (the issue that directly affects them), e.g., people with disabilities caring about other people with disabilities or the operators who deal with disabilities. They are important information and communication functions, but if I want to implement a process of change, I must listen to those who are furthest away from disability and may not even want to hear about it. You may miss something, even so, in the richness and articulation of contents to acquire breadth (and depth) of communicative action. We must not forget that rooted popular stereotypes are not very rich or articulated in terms of information, but they are widely present in the mainstream and often right on prevention issues. Building popular prevention communication does not mean trivialization and simplification of the messages and content, but that messages and content can be decoded and interpreted by many.

(2) Looking for narratives. Narratives are the second important dimension of our strategy. Human life, history, and biography, is our first story. The narrative approach (Bruno \& Lombardinilo, 2016) to prevention communication means not only finding stories in the media, but gaining the ability to discover, collect, and 
analyze stories, and then invent, build, and commission new ones, representatives for the community. Stories must not appeal only to us because the stories become narratives if we tell them to others and if others hear them. In addition, we must always keep in mind that there is only the "reality" or the "real" in the stories. The likelihood is that only one is possible and credible from among multiple realities (Schutz, 1972), and a story is deemed credible only if we share it with others. In summary, it is not important to build large, detailed stories, but instead to draw from the "mines" of the stories in social and prevention life, as well as from those that are already present in other corners of the collective imagination.

(3) Rituals. The third dimension is the ritual. Our daily life is full of large and small rituals of which we do not want to go without. For this purpose, ritual also means proposing familiar actions and communication (Couldry, 2012, p. 80). The question we must ask is, "What creates meaning in my land and communicative context?" The question, though, is that very often what creates meaning is "taken for granted" and is silent since it works from a cultural background that determines common sense. The ritual dimension, by contrast, is a dimension that, behind the apparent static repetition of common sense, can intervene in imagination, modifying it. In practice, it means being systematically reproduced and easily identified by the inhabitants of a territory of prevention communication activities without fear of being "repetitive" because one of the goals is just that.

(4) Colonizing the collective imagination (Peruzzi \& Volterrani, 2016, p. 220). The fourth dimension is that of colonization to which we referred earlier. The imaginary proposed by the actors who act in the market are not "evil" and, above all, make up the central part of the frame; they are the most widespread and popular, and also the most democratic. The profit actors are appropriate in a time of popular social imaginary, which considers using them to expand or build new market space. As a counterpoint, third sector organizations or public organizations could do the same using widespread and used imaginary as part of the market to promote new social imaginary. This does not mean the flattening of market strategies or transfer of cultural patterns prevailing in the market, but recognizing what are now standard in the archive of images and imaginary and using them by offering an intelligent and creative remix that can support different but contiguous perspectives.

(5) Media education. Finally, the last dimension refers to media education (Buckingham, 2003). Despite the many paths of learning and spread of pedagogical aspirations of many of the social issues of most organizations, the potential of sharing common media education is not perceived, not only in the context of the school and young people, but also as one of the cornerstones of lifelong learning. It is through these medium- to long-term paths that people acquire the skills to understand, analyze, and individually and collectively build media culture, thereby helping to build cultures and innovative collective imagination.

\section{The Ethical Question}

But there is a fundamental difference that should denote the communication of social problems: the ethical question (Couldry, Madianou, \& Pinchevsky, 2013).

At least three questions should be asked each time. The first is whether what we are doing will allow us to change the individual and collective well-being of the communities where we act and in which direction. Not always changing perception brings with it an improvement in the quality of life. In some cases, it is likely to be exactly the opposite. The second is whether what we are doing causes or will cause verbal and/or direct and/or indirect material injuries to the persons involved (directly or indirectly). If I want to change the perception of widespread violence in a neighborhood, I have to assess whether the communication activities that I am 
proposing put third parties unaware of what is happening in real danger. The third question, perhaps the most difficult, is whether we can do what other organizations are doing for a supposed and imagined supreme good of communities. Arrogating the right to know what is and will be the good of the communities where we act is often one of the mistakes made by third sector organizations that do not work for the social development of the communities, but instead for their own development.

But reasoning about ethics for those who work in and with contemporary media on perceptions means being aware that whenever we communicate, something will happen and that the constant change of tools, spaces, and modes forces us to think about possible contradictory consequences.

\section{Conclusions}

In conclusion, talking about communication of social problems today means addressing the problem of cultural production.

Often many organizations and experts have underestimated this aspect because it has been deemed secondary to social action. An error has been paid for dearly because, as we have seen, the space was occupied mainly by the market culture. The available space is limited, and it is difficult to act if approaches, communication methods, and actions are not changed.

Precisely for this reason it is important to accept the challenge of innovation that lies in the ability to design communication of social problems which has the means to promote and legitimize the growing presence in the available media space through fascinating and diffusible products and credible narratives.

The hope is that they do not remain only ideas, but instead become instruments of daily action in organizations that have social change at heart.

\section{References}

Bentivegna, S. (2009). Disuguaglianze digitali (Digital inequalities). Roma-Bari: Laterza.

Bentivegna, S., \& Boccia Artieri, G. (2019). Le teorie delle comunicazioni di massa e la sfida digitale (The theories of mass communications and the digital challenge). Roma-Bari: Laterza.

Bruno, M., \& Lombardinilo, A. (2016). Narrazioni dell'incertezza: Società, media, letteratura (Narratives of uncertainty: Society, media, literature). Milano: FrancoAngeli.

Boccia Artieri, G. (2016). Stati di connessione (Connection states). Milano: FrancoAngeli.

Boccia Artieri, G., Gemini, L., Pasquali, F., Carlo, S., Farci, M., \& Pedroni, M. (2017). Fenomenologia dei social network (Phenomenology of social networks). Milano: Guerini Scientifica.

Buckingham, D. (2003). Media education: Literacy, learning and contemporary culture. Cambridge: Polity Press.

Buonanno, M. (2008). The age of television: Experiences and theories. Bristol: Intellect Ltd.

Couldry, N., Livingstone, S., \& Markham, T. (2010). Media consumption and public engagement: Beyond the presumption of attention. New York: Palgrave Macmillan.

Couldry, N., Madianou, M., \& Pinchevsky, A. (2013). Ethics of media. London: Palgrave Macmillan.

Couldry, N., \& Hepp, A. (2017). The mediated construction of reality. Cambridge: Polity Press.

Couldry, N., \& Mejias, U. A. (2019). The costs of connection: How data is colonizing human life and appropriating it for capitalism. New York: Stanford University Press.

Couldry, N. (2012). Media, society, world: Social theory and digital media practice. Cambridge: Polity Press.

Couldry, N. (2016). Live with the media manifold. In L. Kramp, N. Carpentier, A. Hepp, R. Kilborn, R. Kunelius, H. Nieminen, ... S. Tosoni (Eds.), Politics, civil society and participation: Media and communications in a transforming environment (pp. 25-39). Bremen: Edition Lumière.

Curran, J. (2011). Media and democracy. London: Routledge.

Dahlgren, P. (2009). Media and political engagement: Citizens, communication and democracy. Cambridge: Cambridge University Press. 
Dahlgren, P. (2013). The political web: Media, participation and alternative democracy. New York: Palgrave Macmillan.

Durand, G. (1960). Les structures anthropologiques de l'imaginaire (The anthropological structures of the imaginary). Grenoble: Allier.

Elias, N. (1978). What is sociology? London: Hutchinson.

Ervas, F., \& Gola, E. (2016). Che cos'è una metafora (What is a metaphor). Roma: Carocci.

Hofstadter, D., \& Sander, E. (2011). Surfaces and essences: Analogy as the fuel and fire of thinking. London: Basic Books.

Horsley, J. S. (2016). Media framing of disaster. In A. Schwarz, M. W. Seeger, and C. Auer (Eds.), The handbook of international crisis communication research (pp. 155-164). Chichester: Wiley and Sons.

Jedloswki, P. (2008). Immaginario e senso comune (Imaginary and common sense). In F. Carmagnola and V. Matera (Eds.), Genealogie dell'immaginario (Genealogies of the imaginary) (pp. 222-238). Torino: Utet Università.

Jenkins, H. (2006). Convergence culture. New York: New York University Press.

Lakoff, G. (2014). The all new don't think of an elephant!: Know your values and frame the debate. New York: Chelsea Green Pub Co.

Murray, C., Schrøder, K., Drotner, K., \& Kline, S. (2003). Researching audiences: A practical guide to methods in media audience analysis. London: Arnold Publications.

Peruzzi, G., \& Volterrani, A. (2016). La comunicazione sociale (Social communication). Roma-Bari: Laterza.

Rosa, H. (2013). Social acceleration: A new theory of modernity. New York: Columbia University Press.

Sennett, R. (2008). The craftsman. New Haven: Yale University Press.

Schutz, A. (1972). Collected papers I. The problem of social reality. London: Springer.

Schwarz, A., Seeger, M. W., \& Auer, C. (2016). The handbook of international crisis communication research. Chichester: Wiley and Sons.

Silverstone, R. (1994). Television and everyday life. London: Routledge.

Sloman, S., \& Fornbach, P. (2018). The knowledge illusion: The myth of individual thought and the power of collective wisdom. London: Palgrave Macmillan.

Sorice, M. (2019). Partecipazione democratica. Teorie e problemi (Democratic participation. Theories and problems). Milano: Mondadori Università.

Van Djiek, J., Poell, T., \& De Waal, M. (2018). The platform society: Public values in a connective world. Oxford: Oxford University Press.

Vergani, E. (2012). Costruire visioni (Building visions). Roma: Exorma Edizioni.

Volterrani, A. (2011). Saturare l'immaginario (Saturate the imaginary). Roma: Exorma Edizioni.

Volterrani, A. (2016). How to build prevention for the elderly and disabled before natural disasters? The added social value of voluntary organizations in Europe. Sociology and Anthropology, 4(2), 92-98.

Volterrani, A. (2018). Participation and communication in the time of social media: A chimera or an opportunity. Sociology Study, 8(5), 213-219. 